\title{
Drivers' Tactics in Ridesharing Economy in the Philippines
}

Laiza L. Limpin

College of Computer Studies

De La Salle University - Manila

Metro Manila, Philippines

Email: laiza_limpin@dlsu.edu.ph

\section{Raymund C. Sison}

College of Computer Studies

De La Salle University - Manila

Metro Manila, Philippines

Email: raymund.sison@delasalle.ph

\section{Abstract}

Increasing mobility needs, coupled with the lack of adequate public transportation has led to the popularity of ridesharing services in the Philippines, which in 2015 became the first country to implement a regulatory framework for ridesharing through transportation network company (TNC) apps. This study aims to explore the participation of drivers in the ridesharing economy in Metro Manila. Employing thematic analysis, the driver tactics are viewed as falling under one of six categories: surge chasing, request skipping, dual driving, colorum, operator tactics and focusing. While many of the themes confirm the findings of earlier studies, some ridesharing tactics found in the Philippine context provide nuances that may offer insights on the drivers' use of ridesharing platforms. Specifically, these strategies suggest that users find new ways to use the technology to support their motivations, resulting in a notion deviant to the original purpose of ridesharing.

Keywords Ridesharing, Driver strategies, Tactics, Sharing Economy 


\section{INTRODUCTION}

Ridesharing is one of the growing sharing economy which provided an alternative means of transportation in many developed and developing countries. It allows an individual to co-use a vehicle for a trip, arranged through a transportation network company (TNC) applications (e.g., Uber, Lyft, Grab), thereby sharing the costs with the owner. Ridesharing has played an important role in the transportation system today and new developments in technology and the social media has presented opportunities to increase ridesharing use worldwide.

The Philippines is one of the wide adopters of ridesharing services with an estimated 2.96 million users in 2018 and is expected to hit 5.4 million by 2022 (Statista 2018a). Consequently, the Philippines became the first country to develop nationwide ride-hailing regulations, which allowed app-based transportation services to operate legally anywhere in the nation (Toppa 2015). The increasing demand for mobility and the lack of adequate mass transport, especially in Metro Manila, was what apparently impelled the legalization of ridesharing services (Morales 2015).

As a result, several ridesharing companies have been established and created opportunities for partners, operators and drivers to provide transportation network vehicle services (TNVS). In October 2015, there were 3,499 applications for TNVS (Sauler 2015) and even with the stringent regulation for entry, TNVS applications pending the approval of the Land Transportation Franchising and Regulatory Board (LTFRB) have ballooned to 119,468 in 2018 (Yee 2018).

The proliferation of ridesharing services could be attributed to the economic benefits, in particular monetary gains, afforded to the drivers (Hamari et al. 2016; Hawlitschek et al. 2016; Malone and Dillahunt 2015; Tussyadiah 2015). For instance, about one-third of the Uber drivers in the United States engaged in the service to earn money while looking for a steady, full-time job (Frizell 2015). This is not inconsistent with the findings of Limpin (2018) who revealed that most Filipino drivers engage in ridesharing services because of the financial benefits they enjoy from the service.

Despite the confirmation of prior studies, there are limited researches that explores the various mechanisms employed by ridesharing drivers in order for them to achieve their goals. In particular, the studies concerning the ridesharing services in the Philippines focus on the comparison of the different ridesharing services with the conventional taxi services and other public means of transportation (Nistal 2016; Paronda et al. 2017, 2016) but did not further investigate the drivers' practices.

And so, this study asks: what are the tactics that the drivers employ in order to achieve their goals and decrease the hassles encountered in providing ridesharing services? By addressing this question, this study contributes to the growing literature on ridesharing applications by presenting findings of a series of research interviews with TNVS providers in Metro Manila Philippines, supplemented with a brief review of the academic literature on ridesharing.

\section{REVIEW OF RELATED LITERATURE}

\subsection{Ridesharing}

Ridesharing refers to a mode of transportation that allows an individual to co-use a vehicle for a trip thereby sharing the costs with the owner. Advantages of ridesharing for participants, to society, and to the environment include savings in travel cost and time while helping to eliminate traffic congestion, conserving fuel and reducing air pollution (Furuhata et al. 2013). It fills empty seats, maximizing vehicle occupancy and helps reduce vehicles on roadway (Shaheen 2014). Through ridesharing companies, nonprofessional drivers of private vehicles can now provide safe, reliable and affordable point-to-point rides and enable the riding public to efficiently get a ride with a tap on a smartphone.

A Statista report (2018b) shows that a worldwide user penetration rate of ridesharing services is at $9.8 \%$ in 2018 and is expected to hit $13.3 \%$ in 2022. In addition, the wide adoption of ridesharing services has gained a worldwide revenue of $\$ 59,678$ million in 2018 and is expected to show an annual growth rate of $16.3 \%$ leading to a market volume of $\$ 109,050$ million by 2022 . The global revenue comparison also shows that most of the revenue is generated in China at a \$29,749 million in 2018.

\subsection{Ridesharing in the Philippines}

Ridesharing services has been gaining popularity as a viable means of transportation in many urban centers in the Philippines, particularly in Metro Manila which suffers from a severe transportation problem (Napalang and Regidor 2017). As a result of its wide adoption, the Philippines was one of the first countries to develop and implement a regulatory framework for TNCs on a national scale legalizing 
app-based car-hailing operations in the country. Defined as "an organization using an online-enabled application or platform technology to connect passengers with drivers using their personal vehicles" (DOTC 2015), TNCs leverage on technology to provide on-demand transport services guaranteeing higher reliability and shorter wait times (Rayle et al. 2016).

\subsubsection{TNCs in the Philippines}

Founded in Malaysia, Grab is a smartphone-based hailing and booking service that operates in eight countries in South East Asia. It was introduced in Metro Manila, Philippines in 2013 and later on expanded its operations in other urban cities including Cebu City, Davao City, Baguio City and Iloilo City. Its services include GrabCar (private cars that can be booked through the platform), GrabTaxi (taxicabs booked through the platform), GrabShare (carpooling services) and GrabExpress (express delivery service) (Grab.com).

New players also entered the ridesharing market in the Philippines. Hype, a Filipino-owned company, launched its operations in Metro Manila in May 2018. The defining feature of Hype is that the public can book a ride through a Short Message Service (SMS), free of charge for both the rider and the driver. Similar with Grab, Hype also offers services such as carpooling, hailing private cars and taxicabs through the app (Hypetransport.com).

Owto, also a Filipino-owned company, started its operations in Metro Manila and parts of Bulacan, Cavite and Rizal in April 2018. Owto features a Silent Distress Signal which riders can use during emergencies while on trip, connecting the rider to the nearest law enforcement team. In addition, the Owto platform allows its riders to set a specific radius where they want to pick up and drop off riders (Owtoph.com).

To provide services in nearby cities and provinces, GoLag, short for "Go Laguna", launched its operations in 2018 to provide services in Laguna, Bulacan, Cavite, Metro Manila and Rizal. GoLag promises lower rates compared to other TNCs, especially during the peak hours and a multi-tier incentive program with loyalty rewards that assures drivers a decent take-home pay (Golag.ph).

\subsection{Driver Strategies}

Ethnographic approaches have shed light on the different strategies made use of by ridesharing drivers. For instance, an ethnographic study on shared taxi drivers' orientations, concerns and practices has revealed the need to focus on the drivers' agency and tempo to allow them to locate passengers in a more ad hoc way (Kasera and Neill 2016). Anderson (2014) categorized drivers as incidentals (those who drive occasionally), part timers (those who use earnings from ridesharing to supplement their monthly income), and full timers (those who consider ridesharing as a job and use it as a primary source of income). In addition, the emergence of the ridesharing phenomenon has also created new labour opportunities and conditions of the driving work itself (Glöss et al. 2016).

Moreover, ridesharing promises to improve the livelihood of the drivers. A study on Chicago Uber partners showed that the use of ridesharing platform Uber helped them make more per hour, even after costs ( $\$ 16 /$ hour after costs) compared to traditional taxi drivers (Hall and Krueger 2015). However, this does not necessarily apply for auto-rickshaw drivers in Bengaluru, India after adopting a P2P application, Ola (Ahmed et al. 2016). For this study, we look into qualitative data to make sense of the strategies and tactics used by ridesharing drivers in Metro Manila, Philippines as they make use of the service.

\section{METHODOLOGY}

This study used a qualitative, inductive approach to explore the different tactics employed by ridesharing drivers in the Philippines. Sampling was purposive. The respondents of this study must have an active registration with a TNC and must have had at least one year of experience as a TNVS provider in Metro Manila, Philippines.

A total of twenty (20) respondents participated in this study. Among the respondents, twelve (12) identified themselves as full time drivers which means that being a TNVS provider is their main job and they drive an average of 12 hours per day. Two (2) of the full time drivers were hired by operators and one (1) is both a driver and an operator. On the other hand, eight (8) among the respondents are driving part time, spending an average of five (5) hours per day working as a TNVS provider. All respondents were male. The respondents were recruited by requesting a ride using the Grab platform. 
To collect information, in-depth interviews were conducted. This method was used following Seidman (1998) who stated "At the root of in-depth interviewing is an interest in understanding the experience of other people and the meaning they make of that experience" (p.3). Interviewing the varied experienced ridesharing drivers is expected to reveal the varying tactics they employ when providing ridesharing services. The interviews were semi-structured and participants were asked open-ended questions. Main questions were formulated by the researcher as a guide for the interview and further probing was done as needed. The questions focused on the perceptions, motivations, practices and tactics they employ when providing ridesharing services. The focus of the study are the drivers as an independent provider and did not include the perspective of the TNC where they are registered.

The interviews ranged from 30 minutes to one (1) hour in length. The interviews were audio-recorded with the consent of the participants while the researchers were taking down notes. The audio recordings were then fully transcribed and the researchers' notes were prepared for data analysis.

The qualitative information obtained was coded, categorized, and analysed using "thematic analysis" (Braun and Clarke 2006). The process included familiarization of the data, coding, searching for themes, reviewing of the themes, defining and naming of the themes and reporting.

\begin{tabular}{|c|c|}
\hline Q: What are your goals and how do you achieve them? & Codes \\
\hline $\begin{array}{l}\text { A: Right now, I need } 50 \text { trips to get the incentive. So in } 3 \text { days, I } \\
\text { should do } 20-20-10 \text { or } 15 \text {. If I want to rest on a Sunday, I need } \\
20-25 \text { trips per day from Monday to Saturday. But that's } \\
\text { difficult. Right now, I only have } 19 \text { trips and I started at } 5: 30 A M \text {. } \\
\text { Once I complete } 22 \text { trips - I don't like driving during the rush } \\
\text { hour. I would rather drive beyond peak hours. You earn a lot } \\
\text { during the rush hour because of the surge but you waste a lot of } \\
\text { time. You'll be stuck in traffic. }\end{array}$ & $\begin{array}{l}\text { - Incentives } \\
\text { - Schedule } \\
\text { - Target trips } \\
\text { - Rush hour driving } \\
\text { - } \text { Surge } \\
\text { - Traffic congestion }\end{array}$ \\
\hline
\end{tabular}

Table 1. Sample of initial coding of data

\section{RESULTS}

The following section presents the findings of this study.

\subsection{Surge Chasing}

To manage the fluctuating supply and demand for rides, TNCs implement surge pricing (Mankin et al. 2017). The surge pricing mechanism is a form of dynamic pricing which enables a temporary increase in the price in an area where the demand for rides is higher than the available cars on the road (Skjelvik et al. 2017).

Surge chasing is a strategy used by some ridesharing drivers to take advantage of the high surge prices. Three surge chasing tactics were identified including technology-assisted surge chasing, events-driven surge chasing and experience-based surge chasing.

\subsubsection{Technology-assisted Surge Chasing}

Technology-assisted surge chasing is a tactic used by drivers to find surge areas using the ridesharing application. Many ridesharing platforms has a heatmap feature, a visualization tool which identifies areas in the city with higher current demand for rides. For instance, the Grab platform represents the heatmap in four different colors to represent the rider demand in a location. Areas shaded in red means that an area has a very high demand, yellow represents the high demand area, green has a medium-level need for rides and spots with no color mean that there are enough drivers in that area to meet the demand.

The drivers use the demand heatmap feature to identify the high demand area and drive to that location. For instance, Bernard (all the driver names used in this paper are fictitious), a full time driver, shares "I use this map to find the location with the highest surge rate. Here, I can see the surge multiplier and I know that the fares are higher in this area".

\subsubsection{Events-driven Surge Chasing}

Higher surge rates are observed during peak hours when fares increase up to twice its normal price. Marlon, a full time driver, takes advantage of this increased price as he relates, "I prefer driving during the rush hour. A lot of people book a ride during this time even if the surge rates are high." 
An increase in the surge rate is also apparent during the holiday season. Leo, a full time driver, is among the drivers who prefer driving during the Christmas season or other holidays as it guarantees a higher fare price. However, in December 2016, the LTFRB received complaints about outrageous price surges ranging from P2000 to P280oo during the holiday season (Dela Paz 2016). As a result, the LTFRB ordered an immediate cap on the surge pricing schemes implemented by the TNCs (Yee 2016).

Surge chasing drivers also keep track of major events like concerts, conventions, festivals, public parties, sporting events, etc. A significant number of people looking for rides during these events ensure a surge in rider demand. For instance, Ryan, a part time driver, relates that he stays in big malls where concerts are held. In addition, John, a part time driver shares, "One of the best times to go online is during the wee hours of Saturdays where many party goers are trying to find a ride home and there are no other means of transportation available."

\subsubsection{Experienced-based Surge Chasing}

An availability check survey revealed that certain areas in Metro Manila such as Makati, Taguig, and Pasay has higher surge rates than other places (Paronda et al. 2016). While others use the demand heatmap feature of the app to identify the high demand areas, for full time and more experienced drivers like Nelson, finding these spots is easy as he shared, "If you've been driving for a long time. You'll know where to go to get more passengers."

In addition, ridesharing drivers are former taxi drivers for several years. With their experience, many of these drivers know the areas in the city where there is a guaranteed demand for trips. For instance, Khalid, a full time driver, relates that he used to be a taxi driver and knows the streets of Metro Manila well. He stays in certain areas like the big malls where he observed a high demand for cars especially during weekends.

\subsection{Request Skipping}

Request skipping is a strategy used by drivers to avoid surge areas and times. The platform allows a driver to accept, cancel or skip a trip request. Cancelling a trip request, however, negatively affects a driver's rating which may result to disqualification for cash incentives. Instead, drivers skip trip requests based on the traffic condition of an area, weather, and the distance.

\subsubsection{Traffic Skipping}

While some drivers chase high surge areas, some opt to avoid them as these places are usually heavilycongested. Remigio, a part time driver, relates that drivers may get stuck because of the heavy traffic thus wasting time and fuel. In addition, some drivers prefer going active outside the peak hours when traffic has subsided even if it also means that the fares are back to its normal rate. Reynaldo, a part time driver, further shares, I only drive at night when traffic is lighter."

Drivers who avoid surge times take on the challenge of finding spots where there are few-to-no drivers around. These places may have lower rider demand but it gives them a steady business because there is little to no competition. Chinggem, a part time driver, indicates, "I like staying in less busy areas. There are fewer requests but I'm not stressed and I can go home anytime because this is near my place."

\subsubsection{Weather-related Skipping}

Habitual transit users are found to use ridesharing services in specific situations such as in bad weather (Nistal 2016). During these times, surge pricing is in effect to encourage more drivers to become available.

However, some drivers skip trip requests during a bad weather condition, in particular during a typhoon, as many streets in Metro Manila can be flooded. For example, Renato, a part time driver, shares that going out in a bad weather is a hassle. He further relates, "It's inconvenient to drive when it's raining. My car might get trapped in the flood and it's not worth the payment to have it fixed or cleaned."

\subsubsection{Distance-based Skipping}

The drivers also tend to skip requests based on some factors like pick up location, destination and times of day. Many of the drivers indicate that at the end of their working day, they can set a home destination before finally going offline. With this, they only accept requests which are towards their home destination and skip those which are going to the opposite direction. Ryan, a part time driver shares, "When I started as a partner, I got a request that was too far from my target home destination. I got home really late so I had to skip work the next morning... So now, I skip those requests." 
Moreover, drivers also consider the pickup location of the rider. Most drivers are not willing to accept trips whose pickup location is more than $2 \mathrm{kms}$. Leo, a full time driver, indicates, "We were told that pick up location should only be within $1 \mathrm{~km}$. But sometimes, the pick up is $4 \mathrm{~km}$ away."

Lastly, drivers who avoid surge areas are those who drive for the enjoyment of driving, getting out of their routine, exploring the city and having some nice conversations. For instance, Raymond, a part time driver relates that he enjoys meeting different types of people when he's driving. Israel, on the other hand, drives part time and enjoys ridesharing because he can help and serve the riders.

\subsection{Dual Driving}

In the Philippines, there are four registered TNCs including Grab, Owto, GoLAg, and Hype (San Juan 2018). In order to entice more partners, these TNCs employ different marketing strategies such as weekly incentives, referral incentives, signup bonuses and other promotions.

To take advantage of these benefits and to ensure a higher income, drivers have devised a strategy called dual driving. Dual driving entails that a driver is registered to at least two TNC and uses their platforms simultaneously to earn more.

\subsubsection{TNC Hopping}

TNC hopping is a common tactic ridesharing drivers use to ensure a higher income. A driver who hops from one TNC to another takes advantage of the TNC's offer, particularly weekly cash incentives. Benny, a full time driver, relates that he was pirated from another TNC. He further shares, "I started in [TNC1] and then [TNC2] pirated us. They offered a big incentive so we were encouraged to join. My old TNC had a good incentive program, but this new TNC gave us two sets of incentives... The income was so good I was able to buy my own car."

In addition, drivers hop to another TNC who deducts a lower commission rate. Israel indicates, "I'm moving to TNC2 by the end of the month. Their commission rate is way lower than my current TNC. My take home pay will be better."

\subsubsection{Dual-apping}

Consequently, drivers who are registered in multiple TNCs employ a tactic called dual-apping. Dualapping allows them to have at least two active ridesharing accounts using different platforms. Dual drivers enjoy more trip requests and a higher revenue, as they get the opportunity of serving more passengers from multiple platforms.

Drivers switch from one application to another for two reasons: 1. Trip requests in one app is low; 2. Another TNC offers a better cash incentive. Dual drivers activate the platform where he will enjoy more benefit. Francis, a full time driver, shares "If the business is slow in [TNC1], I go online on another platform." Roberto, another full time driver, further adds, "We don't get topups from the other TNC that's why I moved here."

\subsection{Operator Tactics}

The business model of many ridesharing companies allow individuals who owns a car to earn money by providing ridesharing services. Consequently, it lets people who needs a ride to book these drivers via a mobile platform. However, the business model of many TNCs in the Philippines has seemingly changed as operators have emerged and started embracing the regular taxi operator strategy to earn more income.

An operator is a private car owner who dispatches multiple cars for ridesharing hiring drivers who may be a relative, a peer, or in some cases, previous taxi drivers to drive their car and earn money for them. For instance, Francis shared, "I registered two cars and let my cousins drive. Then I got another one and drive it myself."

\subsubsection{Boundary System}

Operators have also adopted the payment schemes employed by regular taxi operators to govern the compensation of their drivers. One common payment scheme is the boundary system. In the boundary system, the operator sets a daily quota which the driver has to meet by the end of the day. The driver's daily earnings are remitted to the operator less the excess of the boundary which represents the driver's compensation. For instance, Ruel, a full time driver hired by an operator, was given a P10oo daily boundary. Anything in excess of the P100o will be Ruel's share of the income. 


\subsubsection{Hatian System}

On the other hand, in a hatian (translated as "sharing" in English) system, the operator and the driver gets into a sharing agreement. The agreement may be 50-50 where they equally divide the daily earnings and expenses or $60-40$ scheme where the operator gets $60 \%$ of the earnings and will shoulder all expenses and $40 \%$ goes to the driver. Bernard, a full time driver, shares, "I and my operator agreed to equally share all earnings, maintenance costs and incentives".

\subsection{Colorum}

Although ride-sharing services has been legalized in the Philippines, the LTFRB has suspended the acceptance and approvals of new TNVS applications pending the review of the policies governing appbased hailing services in the country. More than 15,000 out of 32,000 TNVS transport franchise requests have been dismissed leaving thousands of pending applications (Cordero 2017). However, many TNCs have continued to accept applications and allowing their partners to operate which further introduced colorum partners. Colorum partners may be fined as much as P200,000 when apprehended.

\subsubsection{Colorum Driving}

Similarly, colorum driving may also refer to drivers taking trips on the side to earn more money. Some drivers have established a patron-client relationship with their drivers. Because of this, the drivers encourage their patrons to reserve their ride by texting or calling the driver ahead of time and not by requesting using the ridesharing app. Such tactic allows the partners to save the TNC commission taken out from the total amount of the fare. Ronaldo, a full time driver, shares "My neighbour rides with me every day without using the app. I pick her up on my way out and drops her off to her destination."

\subsubsection{Kontrata System}

The kontrata (translated as "contract" in English) system is a tactic employed by drivers for trips whose destinations are outside Metro Manila. The long-distance trips are not beneficial to the drivers as there is no guarantee of having a rider on the return trip. The kontrata tactic may happen before or upon pick up. Negotiating before the pick up involves the driver sending a message to the rider through the app or SMS. Once the rider agrees to the terms, the driver goes to the pick up location and asks the rider to cancel the booking request.

On the other hand, other drivers negotiate upon picking up the passenger. Once the driver is in the pick up location, the driver and the passenger negotiates the terms and once an agreement has been reached, the driver asks the rider to cancel the booking request. Leo shares, "I ask the rider if they could pay a little bit more than what the app showed. Because who will cover my expense going back? I might not get a rider."

Such tactic is deemed beneficial for both the driver and rider, but may be detrimental to the TNC. The platform determines the fare for the trip and is used as a basis for the negotiation. While both the driver and the rider may save from the negotiation, the TNC loses its commission from the trip. Ruel shares "Sometimes, I get requests and the drop off is outside Metro Manila... I ask the rider if he/she is willing to cancel the booking and I will give a discount. If the rider agrees, I save the commission the TNC is supposed to deduct. It's a win-win."

\subsection{Focusing}

Focusing is a strategy that involves limiting the driver's ridesharing activity based on factors like time, number of trips and area. The tactics that emerged include time-based focusing and area-based focusing.

\subsubsection{Time-based Focusing}

For full time drivers, they consider ridesharing as their primary source of income and as a result, they spend an average of 12 driving hours per day. On the other hand, part time drivers who spend an average of five (5) hours per day, use their earnings in ridesharing to supplement their monthly income, to pay personal expenses or to share the costs of their daily trip to and from work. Raymond, a part time driver, shares, "A relative encouraged me to sell my old car and to buy a new one which I can register to a TNC. I use whatever I earn from rideshare driving to pay the car's amortization."

Incentives are regularly given by TNCs to encourage its partners to make more trips. They set a quota which the partners must reach in order to qualify for the cash incentive. Consequently, drivers set their personal daily trip target to maximize their earnings and ultimately, to reach the required quota. Ronaldo shares, "If I want to rest on a Sunday, I have to make 20-25 trips per day." 


\subsubsection{Area-based Focusing}

Area-based focusing is a tactic used by drivers to maximize high demand areas. Drivers focus their destination in common business districts where there are steady trip requests and where trips tend to be short and within the area only. Khalid shares "I get a lot of pool requests in areas where the business process outsourcing (BPO) companies are. A lot of the call center agents book a ride especially at night." In addition, Ronaldo relates that the passenger turnover in these areas is fast which makes it easier for them to reach their daily trip target in a shorter period of time.

In addition, once the driver gains his momentum, staying online and in areas where he gets a continuous trip request is necessary. Marlon shares "Once I drop a passenger off, another request comes in. Sometimes, even before I drop the passenger off... If you stop, you'll lose your momentum and the chance to get more trips. In addition, Darwin, shares "Sometimes I drive for more than 24 hours. I rest a little bit then go out again. Sometimes, while waiting for a request, I'd pull over and take a nap while the app is online. When I get a request, I go again."

\section{DISCUSSION}

This study conceptualized from interview data six themes that describe the different strategies and tactics drivers employ when providing ridesharing services. These themes include Surge Chasing, Request Skipping, Dual Driving, Operator Tactics, Colorum and Focusing. While some of the themes confirm the findings of earlier studies (see Table 2), ridesharing tactics in the Philippine context provide nuances that may offer insights on the use of ridesharing platform. Specifically, these tactics suggest that users find new ways to use the technology to support their motivations.

\begin{tabular}{|c|c|c|}
\hline Driver Strategies & Driver Tactics & $\begin{array}{l}\text { Tactics Found in the } \\
\text { Literature }\end{array}$ \\
\hline \multirow{3}{*}{ Surge Chasing } & Technology-assisted surge chasing & Chen et al. 2016 \\
\hline & Events-driven surge chasing & Chen et al. 2016 \\
\hline & Experience-based surge chasing & Anderson 2014 \\
\hline \multirow{3}{*}{ Request Skipping } & Traffic skipping & Ahmed et al. 2016 \\
\hline & Weather-related skipping & Brodeur and Nield 2018 \\
\hline & Distance-based skipping & $\begin{array}{l}\text { Ahmed et al. 2016; Brodeur and } \\
\text { Nield 2018; Kasera and Neill } \\
2016\end{array}$ \\
\hline \multirow[t]{2}{*}{ Dual Driving } & TNC hopping & Jiang and Zhang 2018 \\
\hline & Dual-apping & Jiang and Zhang 2018 \\
\hline \multirow{2}{*}{ Operator Tactics } & Boundary System & \\
\hline & Hatian System & \\
\hline \multirow{2}{*}{ Colorum } & Colorum Driving & \\
\hline & Kontrata System & \\
\hline \multirow{2}{*}{ Focusing } & Time-based focusing & $\begin{array}{l}\text { Anderson 2014; Kasera and Neill } \\
2016\end{array}$ \\
\hline & Area-based focusing & $\begin{array}{l}\text { Ahmed et al. 2016; Kasera and } \\
\text { Neill } 2016\end{array}$ \\
\hline
\end{tabular}

Table 2 Themes in the Qualitative Data: Driver Strategies and Tactics

Surge chasing has been observed amongst Uber drivers who further extend their sessions and provide significantly more rides as a response to higher surge rates (Chen et al. 2016). In addition, rickshaw drivers using the Ola platform in Bengaluru, India also prefer driving in locations where a higher passenger demand is observed. Some rickshaw drivers were also observed to avoid these locations depending on the traffic condition (Ahmed et al. 2016).

The result of this study also reveals that some drivers avoid driving during bad weather conditions. However, this result differs to observed increase in the number of Uber rides in New York City during rainy days (Brodeur and Nield 2018). In addition, Filipino riders tend to become undecided about booking a rideshare during rainy days because of the surge rate (Nistal 2016).

Colorum driving is one of the tactics that TNVS providers employ to supplement their daily earnings. The term colorum is a slang for illegal public land transport in the Philippines. However, in the context of ridesharing, colorum activities refer to a driver going offline and doing sideline trips. These trips are not recorded in the app thus allowing the drivers to save the $20-25 \%$ TNC fee and generate extra income. 
In addition, the kontrata system, has emerged as a tactic amongst ridesharing drivers. The kontrata system is a common practice amongst taxi drivers in Metro Manila where a passenger pays a fixed and often excessively high fare. The kontrata system has been a common problem in riding a regular taxi in Metro Manila as most drivers refuse to use the meter and demand the passenger to get into a "kontrata" (Nistal 2016). With colorum driving and the kontrata system emerging in ridesharing services, the passengers may perceive the drivers as abusive and snobbish leading to the detriment of the service.

Moreover, ridesharing is assumed to reduce car use and ownership as it is a shared mode of transportation rather than purchasing new vehicles (Jin et al. 2018). However, the result of this study reveals that some of the practices do not conform with the true essence of ridesharing. The findings reveal that some ridesharing partners in the Philippines were encouraged to buy new cars with the intention to use them as transport network vehicle. As a matter of fact, a report reveals that TNVS has boosted the car sales in the Philippines (Lorenciana 2017), with small sedans being the most popular among prospect TNVS providers.

The adoption of ridesharing services in the country has further led to the emergence of operators who function similarly with regular taxi operators deploying multiple vehicles to provide ridesharing services. As such, the experience of ridesharing in the Philippines, particularly in Metro Manila, does not reflect one of the primary objectives of ridesharing services which is to reduce car use and ownership. In fact, it can be argued that the popularity of ridesharing services has led to the increase of vehicles roaming the streets of Metro Manila as the operations of TNCs does not differ from that of taxis with most ridesharing drivers driving full time rather than part time (Paronda et al. 2017).

The above-mentioned practices finally reveal that the drivers were primarily interested in increasing their earnings from ridesharing. Therefore, ridesharing in Metro Manila is considered as "entrepreneurial" (Nistal 2016). However, "entrepreneurial" drivers are not only true for developing countries like the Philippines but is also proliferated in developed countries such as the United States (Anderson 2014).

\section{CONCLUSION AND FUTURE DIRECTION}

In conclusion, this study has identified dominant driver strategies and tactics in the context of the Philippine ridesharing economy. Some of the strategies, including surge chasing, request skipping, dual driving and focusing, and their variants were found to confirm findings of previous studies.

Nevertheless, the novelty of this paper lies in the strategies and tactics that were found to be unique in the Philippine setting. These strategies suggest that users find new ways to use the technology to support their motivations, resulting in a notion deviant to the original purpose of ridesharing. In addition, the tactics like colorum driving, the kontrata system, the boundary system, hatian system are not unfamiliar for Filipino drivers and commuters as these are common tactics employed by conventional taxi drivers and other public utility vehicle providers.

Furthermore, the findings of this study may have implications towards the improvement of ridesharing services in the country. For instance, the result of this study could help the TNCs to provide better services to help their partners in achieving their goals and to ensure that tactics that negatively impact both the drivers and the riders will be avoided.

This study is not without limitation. The respondents of this study are limited to a small sample of ridesharing drivers within Metro Manila only. Therefore, further studies with a larger sample size including drivers in other urban areas where ridesharing services are available should be conducted. Finally, because this research is exploratory in nature, future research should test and verify the propositions in different contexts to support the applicability of the scales and generalizability of the findings in this study.

\section{References}

Ahmed, S. I., Bidwell, N. J., and Neill, J. O. 2016. "Peer-to-Peer in the Workplace: A View from the Road," Proceedings of the SIGCHI Conference on Human Factors in Computing Systems. (https://doi.org/10.1145/2858036.2858393).

Anderson, D. N. 2014. "Not Just a Taxi'? For-Profit Ridesharing, Driver Strategies, and VMT," Transportation (41:5), pp. 1099-1117. (https://doi.org/10.1007/s11116-014-9531-8).

Braun, V., and Clarke, V. 2006. "Using Thematic Analysis in Psychology," Qualitative Research in Psychology (3:2), pp. 77-101. (https://doi.org/10.1191/1478088706qpo63oa). 
Brodeur, A., and Nield, K. 2018. "An Empirical Analysis of Taxi , Lyft and Uber Rides : Evidence from Weather Shocks in NYC R," Journal of Economic Behavior and Organization (152), pp. 1-16.

Chen, M. K., Sheldon, M., Bell, F., Chevalier, J., Hall, J., Nalebuff, B., Snider, C., and Spaeth, M. 2016. "Dynamic Pricing in a Labor Market: Surge Pricing and Flexible Work on the Uber Platform," in EC '16 Proceedings of the 2016 ACM Conference on Economics and Computation, pp. 455-455.

Cordero, T. 2017. "LTFRB Dismisses 15,00o Franchise Applications for Uber and Grab | Money | GMA News Online," GMA News Online. (http://www.gmanetwork.com/news/money/companies/594791/ltfrb-dismisses-15-ooofranchise-applications-for-uber-and-grab/story/, accessed March 2, 2018).

Departemen Transportation and Communication Philippines. 2015. "Department Order No.97-1097 to Promote Mobility," Department of Transportation and Communications (DOTC). (http://dotr.gov.ph/index.php/2014-09-03-06-32-48/2014-09-03-06-44-58\#y2015).

Frizell, S. 2015. "All the Things You Ever Wanted to Ask Your Uber Driver, Answered | Time.Com," Time. (http://time.com/3678507/uber- driver-questions/, accessed August 4, 2018).

Furuhata, M., Dessouky, M., Ordóñez, F., Brunet, M.-E., Wang, X., and Koenig, S. 2013. Ridesharing: The State-of-the-Art and Future Directions.

Glöss, M., Mcgregor, M., and Brown, B. 2016. "Designing for Labour: Uber and the On-Demand Mobile Workforce," in CHI '16 Proceedings of the 2016 CHI Conference on Human Factors in Computing Systems, pp. 1632-1643. (https://doi.org/10.1145/2858036.2858476).

Hall, J. V, and Krueger, A. B. 2015. "An Analysis of the Labor Market for Uber's Driver-Partners in the United States.”

Hamari, J., Sjoklint, M., and Ukkonen, A. 2016. "The Sharing Economy: Why People Participate in Collaborative Consumption," Journal of the Association for Information Science and Technology (67:9), pp. 2047-2059. (https://doi.org/10.1002/asi.23552).

Hawlitschek, F., Teubner, T., and Weinhardt, C. 2016. "Trust in the Sharing Economy," Die Unternehmung (70:1), pp. 26-44. (https://doi.org/10.5771/0042-059X-2016-1-26).

Jiang, W., and Zhang, L. 2018. "Evaluating the Effects of Double-Apping on the Smartphone-Based EHailing Service: A Simulation-Based Study,” IEEE Access (3536:c), pp. 1-1. (https://doi.org/10.1109/ACCESS.2018.2797207).

Jin, S. T., Kong, H., Wu, R., and Sui, D. Z. 2018. "Ridesourcing, the Sharing Economy , and the Future of Cities," Cities (October 2017), Elsevier, pp. o-1. (https://doi.org/10.1016/j.cities.2018.01.012).

Kasera, J., and Neill, J. O. 2016. "Sociality, Tempo \& Flow : Le Arning from Namibian Ride - s Haring," Proceedings of the First African Conference on Human Computer Interaction - AfriCHI'16.

Limpin, L. 2018. "Investigating the Factors Influencing the Participation in Ride-Sharing: The Case of the Philippines," in Proceedings of 2018 the 8th International Workshop on Computer Science and Engineering (WCSE 2018), Bangkok, pp. 374-379.

Lorenciana, C. 2017. "Business Uber and Grab Boost Car Sales," The Freeman. (https://www.pressreader.com/philippines/the-freeman/20170316/282660392231134).

Malone, A., and Dillahunt, T. R. 2015. "The Promise of the Sharing Economy among Disadvantaged Communities," in ACM Human Factors in Computing System. (https://doi.org/10.1145/2702123.2702189).

Mankin, J. A., Rivas, J. A., and Jewell, J. J. 2017. "Ride Sharing: A Good Choice for Entrepreneurs?," Journal of Case Studies (35:2).

Morales, N. J. 2015. "Philippines Issues Rules on Ride-Sharing Services, as Taxis Threaten Court | Reuters,” Reuters. (http://www.reuters.com/article/us-philippines-uberidUSKBNoNY15Y20150513).

Napalang, M. S., and Regidor, J. R. 2017. "Innovation Versus Regulation : An Assessment of the Metro Manila Experience in Emerging Ridesourcing Transport Services," Journal of the Eastern Asia Society for Transportation Studies (12).

Nistal, P. D. 2016. "Comparative Study of Uber and Regular Taxi Service Characteristics," in 23rd Annual Conference Transportation Science Society of the Philippines. 
Paronda, A. G. A., Regido, J. R. F., and Napalang, M. S. G. 2016. Comparative Analysis of Transportation Network Companies ( TNCs ) and Conventional Taxi Services in Metro Manila, (August).

Paronda, A. G., Paronda, A. G. A., and Gaabucayan-napalang, M. S. 2017. An Exploratory Study on Uber, GrabCar , and Conventional Taxis in Metro Manila An Exploratory Study on Uber, GrabCar, and Conventional Taxis in Metro Manila, (September).

Dela Paz, C. 2016. "LTFRB Warns Uber, Grab over Unreasonable Price Surge," Rappler. (https://www.rappler.com/business/156495-ltfrb-grab-uber-price-surge, accessed March 12, 2018).

Rayle, L., Dai, D., Chan, N., Cervero, R., and Shaheen, S. 2016. "Just a Better Taxi? A Survey-Based Comparison of Taxis, Transit, and Ridesourcing Services in San Francisco," Transport Policy (45), Elsevier, pp. 168-178. (https://doi.org/10.1016/j.tranpol.2015.10.004).

San Juan, A. D. 2018. “3 Local TNCs Set to Compete with Grab » Manila Bulletin News," Manila Bulletin. (https://news.mb.com.ph/2018/04/05/3-local-tncs-set-to-compete-with-grab/, accessed August $3,2018)$.

Sauler, E. 2015. "LTFRB Exec: Suspend Franchise Applications for App-Based Vehicles | Inquirer News," Philippine Daily Inquirer. (http://newsinfo.inquirer.net/729239/ltfrb-exec-suspendfranchise-applications-for-app-based-vehicles).

Shaheen, S. A. 2014. Introduction to Ridesharing: Overview of Definitions and Setting the Stage.

Skjelvik, J. M., Erlandsen, A. M., and Haavardsholm, O. 2017. "ENVIRONMENTAL IMPACTS AND POTENTIAL OF THE SHARING ECONOMY." (https://www.divaportal.org/smash/get/diva2:1145502/FULLTEXTo1.pdf).

Statista. 2018a. "Ride Sharing - Philippines | Statista Market Forecast." (https://www.statista.com/outlook/368/123/ride-sharing/philippines, accessed August 5, 2018).

Statista. 2018b. "Ride Sharing - Worldwide | Statista Market Forecast." (https://www.statista.com/outlook/368/100/ride-sharing/worldwide\#market-users, accessed August 6, 2018).

Toppa, S. 2015. "Uber Is Now Legal Everywhere in the Philippines | TIME," Time. (http://time.com/3854958/uber-legal-philippines-ride-hailing/).

Tussyadiah, I. P. 2015. "An Exploratory Study on Drivers and Deterrents of Collaborative Consumption in Travel," in Information and Communication Technologies in Tourism 2015, Springer.

Yee, J. 2016. “After LTFRB Warning, Grab, Uber Put Cap on Price Surges | Inquirer News," Inquirer. (http://newsinfo.inquirer.net/856560/after-ltfrb-warning-grab-uber-put-cap-on-price-surges, accessed March 15, 2018).

Yee, J. 2018. "LTFRB Clarifies Who Can Apply First for TNVS Franchise | Inquirer News," Inquirer. (http://newsinfo.inquirer.net/965903/ltfrb-clarifies-who-can-apply-first-for-tnvs-franchise, accessed June 25, 2018).

Copyright: (c) 2018 Limpin \& Sison. This is an open-access article distributed under the terms of the Creative Commons Attribution-NonCommercial 3.0 Australia License, which permits non-commercial use, distribution, and reproduction in any medium, provided the original author and ACIS are credited. 